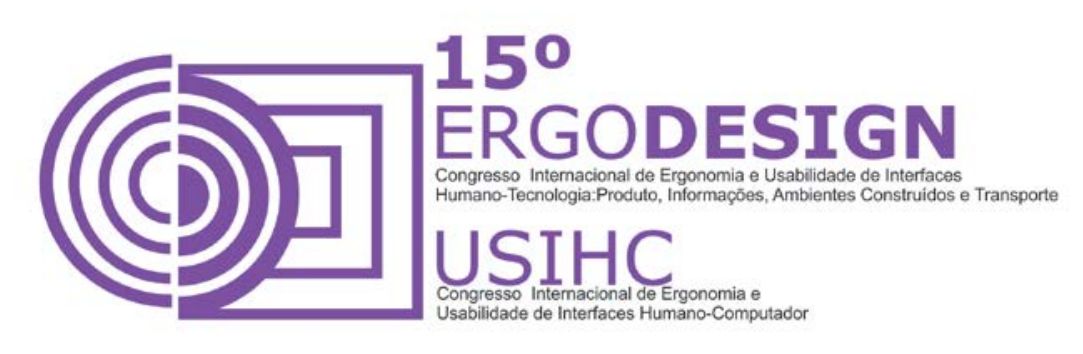

\title{
A IMPORTÂNCIA DA PARTICIPAÇÃO DO USUÁRIO NO DESIGN DE PRODUTOS: ESTUDO DE CASO NO CENÁRIO DA AGRICULTURA
}

\author{
SILVA, Fabiana Raulino da (1); \\ SOARES, Juliana Maria Moreira Soares (2); \\ FONTES, Andrea Regina Martins (3); \\ FERRARINI, Cleyton Fernandes (4); \\ BORRÁS, Miguel Ángel Aires (5)
}

(1) Universidade Federal de São Carlos, Mestranda em Engenharia de Produção,

E-mail: fabi.ergonomia@gmail.com

(2) Universidade Federal de São Carlos, Mestranda em Engenharia de Produção,

E-mail: julianammsoares@gmail.com

(3) Universidade Federal de São Carlos, Doutora em Engenharia de Produção,

E-mail: andreaf@dep.ufscar.br

(4) Universidade Federal de São Carlos, Doutor em Ciência e Engenharia de Materiais,

E-mail: cleyton@ufscar.br

(5) Universidade Federal de São Carlos, Doutor em Engenharia de Produção,

E-mail: maborras@ufscar.br

\begin{abstract}
RESUMO
O principal objetivo deste estudo é relacionar o baixo índice de uso do equipamento de proteção individual (EPI) no trabalho agrícola com o desenvolvimento desse tipo de produto. Busca-se ainda entender como a incorporação de conceitos do desenho universal e usabilidade podem auxiliar nesse processo de projeto. Utiliza-se um estudo de caso a partir de uma abordagem qualitativa por meio de entrevistas semiestruturadas e observações livres de trabalhadores de lavouras de tomate. Os resultados apontam para a pouca interação entre os desenvolvedores de equipamentos de proteção e seus usuários finais, contribuindo com desconforto e pouca adequação a atividade de trabalho.
\end{abstract}

Palavras-chave: ergonomia; design; EPI; desenvolvimento de produtos.

\section{ABSTRACT}

The main aim of this study is to relate the low use rate of personal protective equipment (PPE) in agricultural work with the development of this type of product. Also, this study seeks to understand 


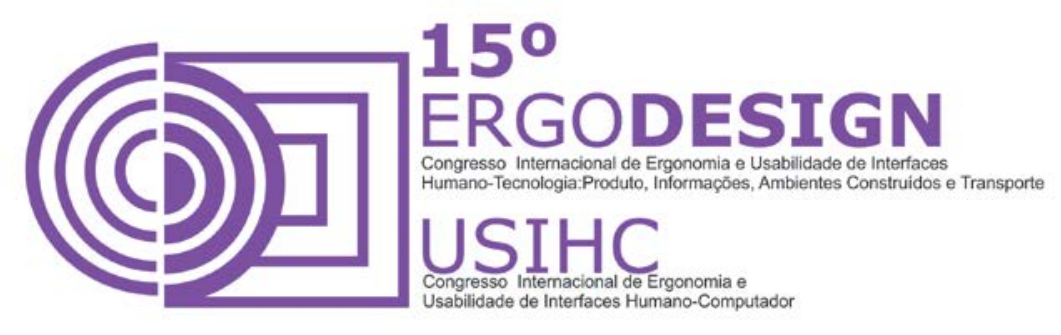

how the incorporation of concepts of universal design and usability can assist in this design process. We use a case study from a qualitative approach through semi-structured interviews and free observations of workers of tomato crops. The results point to the little interaction between developers of protective equipment and its end users, contributing to discomfort and little fitness for work activity.

Keywords: ergonomics; design; PPE; product development.

\section{INTRODUÇÃO}

Entendendo o trabalho como um elemento estruturador essencial das sociedades e de formação humana (OLIVEIRA; SANTOS; CRUZ, 2007), a qualidade de vida do indivíduo imerso nesse meio é um importante ponto a ser atentamente analisado. Dentro da multiplicidade de atividades que constituem as mais diferentes formas de trabalho, muitas delas envolvem uma série de riscos à integridade da pessoa, e o uso do equipamento de proteção individual (EPI) torna-se obrigatório. Neste trabalho destacamos as atividades rurais em lavouras de cultura de tomate, nas quais o trabalhador se mantém em constante contato com a aplicação de produtos químicos com alto grau de toxicidade. Porém, constata-se que o uso de EPI é permeado por uma série de insatisfações, além de se verificar uma resistência por parte de trabalhadores em usar equipamentos de proteção em suas rotinas, apesar de os mesmos terem ciência da necessidade do uso de um aparato preventivo em diversos casos.

Este estudo teve como objetivo de analisar o uso de equipamento de proteção individual na atividade da colheita manual de tomate. Os estudos multicasos foram conduzidos em lavouras situadas nas cidades de Itu e Presidente Prudente, no estado de São Paulo, com a participação de doze trabalhadores rurais ao total, empregados no setor de colheita. Essa pesquisa foi viabilizada através de técnicas como entrevistas semi-estruturadas e observações livres da rotina laboral desses trabalhadores. Como parte dessa análise, buscou-se entender a colaboração de conceitos de ergonomia e design nesse processo, como do desenho universal e de usabilidade, para a concepção de equipamentos mais satisfatórios ao uso desses trabalhadores, segundo as demandas percebidas e relatadas durante as abordagens realizadas para a presente pesquisa.

\section{REFERENCIAL TEÓRICO}

\subsection{Ergonomia no ambiente agrícola}

A palavra ergonomia tem sua origem no grego ergon (trabalho) e nomos (normas, regras, leis) (ABERGO, s/d). Trata-se da ciência que estuda a interação entre o homem e seus sistemas e elementos ao seu redor, tendo como objetivo a otimização dessa relação, através de planejamentos, análises, avaliações de tarefas, produtos e ambientes imersos nesse contexto, entre outras atividades que cabe ao profissional ligado à essa área de atuação (ABERGO, s/d). Ainda, segundo a Associação Brasileira de Ergonomia (s/d):

"Trata-se de uma disciplina orientada para uma abordagem sistêmica de todos os aspectos da atividade humana. Para darem conta da amplitude dessa dimensão e poderem intervir nas atividades do trabalho é preciso que os ergonomistas tenham uma abordagem 


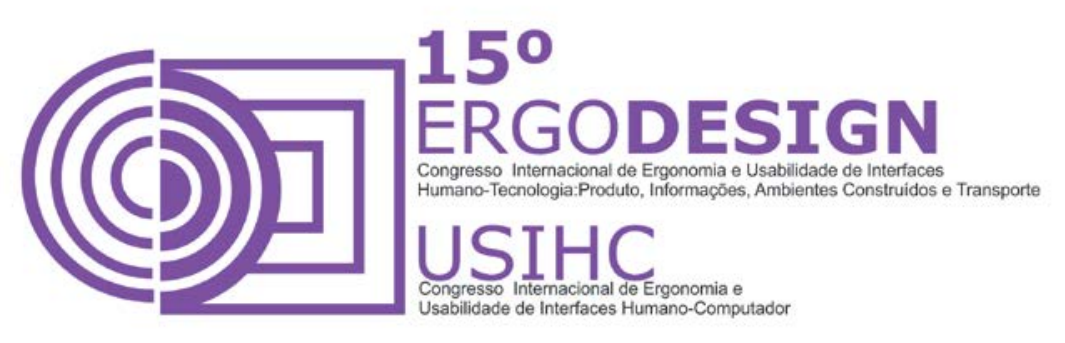

holística de todo o campo de ação da disciplina, tanto em seus aspectos físicos e cognitivos, como sociais, organizacionais, ambientais, etc." (ABERGO, s/d)

Quando se pensa no indivíduo em seu ambiente de trabalho, é possível perceber que uma visão integradora é fundamental para a manutenção da saúde. A ergonomia mostra que a realização de uma tarefa exige um grau de mobilização físico, cognitivo e psíquico do operador para a execução da atividade. Cada tarefa determina constrangimentos específicos que demandam certos esforços do trabalhador. Dessa forma, a carga de trabalho pode ser compreendida como a interação entre constrangimento e esforço. (FALZON, 2007; LIMONGI-FRANÇA, 2008).

Segundo Guérin et al. (2001), "mudar o trabalho, para que todos que o exercem nele encontrem, em sua diversidade, interesse, com a preocupação, ao mesmo tempo, de favorecer a eficiência, a competitividade, eis um projeto essencial ao qual os ergonomistas nos convidam" (GUÉRIN et al., 2001, p. XV). Assim, torna-se fundamental entender a influência da variabilidade encontrada no trabalho ou aquela que pode ser introduzida no ambiente e/ou na sua forma de organização para estimular as pessoas e, assim contribuir para aumentar o nível de atenção, evitando potenciais acidentes e elevando a satisfação na realização das tarefas deste indivíduo no trabalho.

A variabilidade, presente em todas as situações que envolvem o trabalho, a organização deste trabalho e o trabalhador, pode auxiliar na compreensão sobre como os trabalhadores reagem diante da resolução de problemas, entre sua tarefa prescrita e sua atividade real (GRUPO ERGO\&AÇÃO/DEP/UFSCAR, 2003).

Partindo-se do preceito de que as pessoas são diferentes em suas mais diversas nuances, a generalização se torna um problema em projetos de adaptações do trabalho em ergonomia (GUÉRIN et al., 2001). Múltiplas distinções são passíveis de serem feitas entre os seres humanos, sendo possível distinguir os trabalhadores a exemplo dos sexos e de diferenças antropométricas, bem como em relação às distinções de idade, saúde e contextualização social, fazendo com que a variabilidade seja um assunto inerente ao tema do trabalho. Assim podemos considerar como a variabilidade inter-individual aquela que considera as diferenças biocognitivas e o histórico sócio emocional do individuo (GRUPO ERGO\&AÇÃO/DEP/UFSCAR, 2003). Um mesmo posto de trabalho pode ser ocupado por dois indivíduos com diferentes características biomecânicas, levando à diferentes demandas ergonômicas e diferentes mecanismos de resposta entre esses trabalhadores.

As variações intra-individuais referem-se à diversidade entre as pessoas, somando-se a isso as variações do estado de cada um. Se considerarmos as variações em curto prazo, identificaremos as alterações relacionadas aos ritmos biológicos, sendo os mais conhecidos, os ciclos menstruais das mulheres e os ritmos circadianos, considerando-se ainda que os indivíduos sofrem com a influência de outros acontecimentos pessoais tais como familiares, transporte até o trabalho, entre outros (GUÉRIN et al, 2001).

Dentro de uma margem de manobra possível, os trabalhadores desenvolvem estratégias para realizar sua atividade frente às imposições da empresa. As experiências e o aprendizado são contemplados nas decisões tomadas e nas ações dos trabalhadores. Desta forma, podemos dizer que gerenciar as exceções está relacionado com as adaptações que 


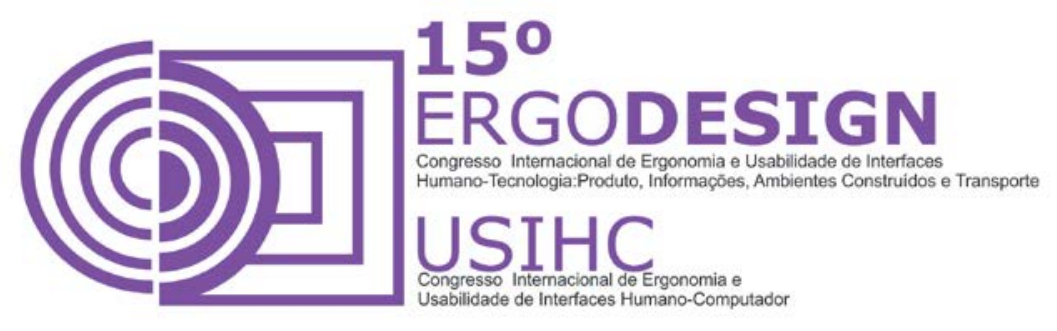

podemos realizar para aproximar o real do prescrito (ABRAHÃO, 2000).

Não apenas as diferenças entre os trabalhadores, mas também a realidade inerente ao ambiente agrícola, interferem na atividade e, consequentemente, na realidade vinculada ao uso dos equipamentos de proteção individual.

O ambiente agrícola possui elementos que lhe conferem complexidade: acontecimentos aleatórios, imprecisão, imprevistos, tarefas sobrepostas, intempéries e condições alheias ao domínio dos trabalhadores (MONTEDO; SZNELWAR, 2001).

\subsection{O Equipamento de Proteção Individual (EPI)}

Segundo a Norma Regulamentadora $n^{0} 6$ (BRASIL, 1978), considera-se um equipamento de proteção individual (EPI) "todo dispositivo ou produto, de uso individual utilizado pelo trabalhador, destinado à proteção de riscos suscetíveis de ameaçar a segurança e a saúde no trabalho." (BRASIL, 1978).

O uso dos EPI's é legalmente disposto mediante a prévia norma citada e pelo Ministério do Trabalho e Emprego (MTE), sendo o fornecimento gratuito desse tipo de material uma responsabilidade do empregador (SIMÕES, 2010), e sua obrigatoriedade de uso deve ser exigida pelo mesmo. Para viabilizar-se sua correta utilização, uma ampla e complexa análise do ambiente de trabalho no qual o trabalhador está inserido é requerida, bem como uma avaliação desse próprio equipamento, checando sua procedência e adequação às características relacionadas a seu contexto de uso (LOPES NETTO; BARRETO, 1996). Multas e sanções legais são previstas ao empregador que descumprir as orientações com relação ao uso de EPI's por parte de seus trabalhadores (ORTOLAN; FALCATO; SOUZA, 2007). Ainda, esse tipo de equipamento deve possuir o Certificado de Aprovação (CA) junto ao Ministério do Trabalho, para que se testem e legitimem sua funcionalidade, viabilizando o comércio do mesmo (TEIXEIRA, 2009). Em princípio, o prazo de validade concedido pelo CA ao produto de proteção é de 5 anos (LOPES NETTO; BARRETO, 1996), podendo ser renovado a posteriori.

Cabe ao empregado fazer o uso correto dos EPI's, em conformidade com o que foi orientado por seu empregador, fazendo o uso do equipamento somente quando necessário, responsabilizando-se por comunicar a este mesmo empregador qualquer mudança de estado desse produto, bem como tornando-se responsável também pela conservação do mesmo (BRASIL, 1978).

Podem ser encontrados diversos tipos de EPI's, a serem classificados em razão de seu uso. e a seguir listam-se alguns deles, de acordo com Norma Regulamentadora 6 (BRASIL, 1978):

- EPI para proteção dos olhos e face;

- EPI para proteção dos membros superiores;

- EPI para proteção dos membros inferiores;

- EPI para proteção respiratória; 


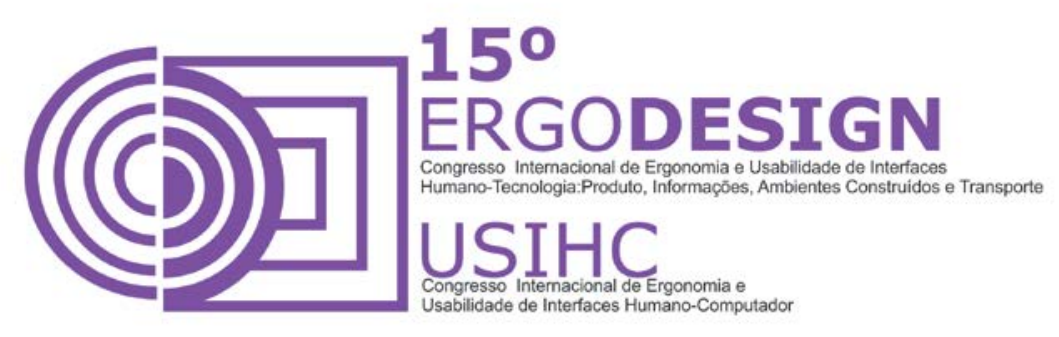

- EPI para proteção da cabeça;

- EPI para proteção auditiva;

- EPI para proteção do tronco;

- EPI para proteção do corpo inteiro;

- EPI para proteção contra quedas com diferença de nível.

A resistência e a falta de uso desse tipo de equipamento no Brasil são situações facilmente encontradas e reportadas em bibliografias da área (ALMEIDA; PERLIN; RUPPENTHAL, 2000; GUIMARÃES et al., 2011; PELLOSO; ZANDONADI, s/d). E esse fato constitui-se em um dado bastante preocupante, na medida em que são listados numerosos acidentes e problemas decorrentes das situações de trabalho no âmbito nacional (GROHMANN, 1997; BRASIL, 2011). Tal panorama demanda a atenção para que sejam realizados mais estudos aprofundados relacionado os motivos da falta de uso dos EPI's.

De acordo com Veiga et al. (2007), os equipamentos de proteção individual são uma das medidas de controle de riscos a serem consideradas após tentar-se eliminar os riscos ou neutralizá-los diretamente em sua fonte. Segundo a mesma fonte, para uma prevenção de riscos eficaz, deve-se analisar a realidade do trabalho e enfocá-lo de forma sistêmica.

Para Veiga et al. (2007) os trabalhadores envolvidos na agricultura se sentem muitas vezes despreparados para participar de projetos técnicos, sentindo-se intimidados em contribuir com sua linguagem para um projeto que possa influenciar diretamente em sua realidade de trabalho. É o caso da participação dos trabalhadores no desenvolvimento de equipamentos de proteção adequados à sua realidade. Nesse sentido destaca-se a importância dos meios para a participação efetiva dos usuários em atividades projetivas. Segundo Fontes (2012, p. 236), o processo de projeto deve ser feito de forma coletiva, integrando os usuários e fazendo-os participar ativamente da construção da solução por meio das interfaces e produções intermediárias.

\subsection{Desenho Universal e Usabilidade}

O surgimento do termo design universal (DU) ocorreu nos anos 1970 na esfera da arquitetura, cunhado pelo americano Ronald L. Mace, porém tão logo se expandiu para outras áreas de produtos de consumo (VANDERHEIDEN, 2000), como meios de comunicação, locomoção, mobiliário e sistemas de informação. Os estudos que levaram esse arquiteto americano ao conceito do design universal foram embasados no livro da britânica Selwyn Goldsmith, Designing for Disabled, publicado em 1963, o qual é considerado uma obra pioneira no assunto da acessibilidade (COLEMAN et al., 2003). Essa terminologia constitui-se em uma segmentação dentro da prática e estudos na área de design, sendo conceituada como um processo no qual designers e desenvolvedores de produtos procuram criar artefatos e serviços que sejam acessíveis a um maior público possível (DTI FORESIGHT, apud DONG et al., 2005). Design universal é um dos termos mais utilizados quando deseja-se abordar o assunto de acessibilidade e inclusão no design, mas ainda usam-se como sinônimos as nomenclaturas chamadas de design inclusivo, design total e design for all. 


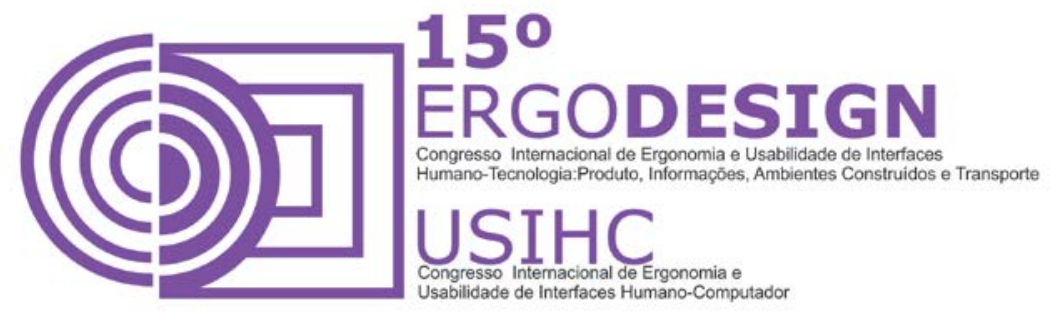

Um dos pré-requisitos para a inclusão dos cidadãos na sociedade é a existência de consistentes graus de acessibilidade e usabilidade nos produtos e serviços, e o design universal busca essa perspectiva pensando no maior número de cidadãos possível. $\mathrm{E}$ ser acessível não significa somente ser alcançável ou manipulável, tendo como significado mais amplo promover a autonomia e segurança ao seu usuário. Para Sassaki (2004), a acessibilidade possui seis esferas distintas, constantes em seis pontos: arquitetônico, comunicacional, metodológico, instrumental, programático e atitudinal. Todos esses âmbitos devem conter características ao alcance de todo cidadão, de maneira igualitária. O College of Design at North Carolina State University (NCSU), um departamento que localiza-se no Center for Universal Design (CUD), da North Carolina University (Estados Unidos), postula que sete são os princípios propostos como os padrões do design universal (tabela 01), as quais servem como diretrizes de aplicação do DU.

Tabela 01. Os sete princípios que norteiam o design universal (NCSU, s/d)

\begin{tabular}{|l|l|}
\hline I) Uso equitativo & $\begin{array}{l}\text { O design deve ser útil e pronto ao comércio a pessoas com múltiplas } \\
\text { habilidades. }\end{array}$ \\
\hline II) Uso flexível & $\begin{array}{l}\text { O design deve ser capaz de acomodar e abranger uma alta variedade de } \\
\text { habilidades e preferências individuais em seu uso. }\end{array}$ \\
\hline $\begin{array}{l}\text { III) Uso simples } \\
\text { e intuitivo }\end{array}$ & $\begin{array}{l}\text { Independente do nível de conhecimento, experiência, concentração e afins do } \\
\text { usuário e questão, o design do produto deve facilitar seu uso e entendimento. }\end{array}$ \\
\hline $\begin{array}{l}\text { IV) Informação } \\
\text { perceptível }\end{array}$ & $\begin{array}{l}\text { A informação do produto deve ser comunicada de maneira fácil a seu usuário, } \\
\text { independentemente das suas habilidades sensoriais ou do ambiente. }\end{array}$ \\
\hline $\begin{array}{l}\text { V) Tolerância ao } \\
\text { erro }\end{array}$ & $\begin{array}{l}\text { O design do produto deve minimizar as consequências no caso de ações } \\
\text { acidentais ou inesperadas. }\end{array}$ \\
\hline $\begin{array}{l}\text { VI) Baixo } \\
\text { esforço físico }\end{array}$ & $\begin{array}{l}\text { O conforto e a eficiência devem ser proporcionados pelo design, causando um } \\
\text { mínimo de fadiga. }\end{array}$ \\
\hline $\begin{array}{l}\text { VII) Tamanho e } \\
\text { espaço } \\
\text { necessários } \\
\text { para } \\
\text { aproximação e } \\
\text { uso }\end{array}$ & $\begin{array}{l}\text { O design deve oferecer apropriados espaços e tamanhos para a aproximação, } \\
\text { alcance e uso independentemente das especificidades do usuário. }\end{array}$ \\
\hline
\end{tabular}

Fonte: NCSU (s/d) 


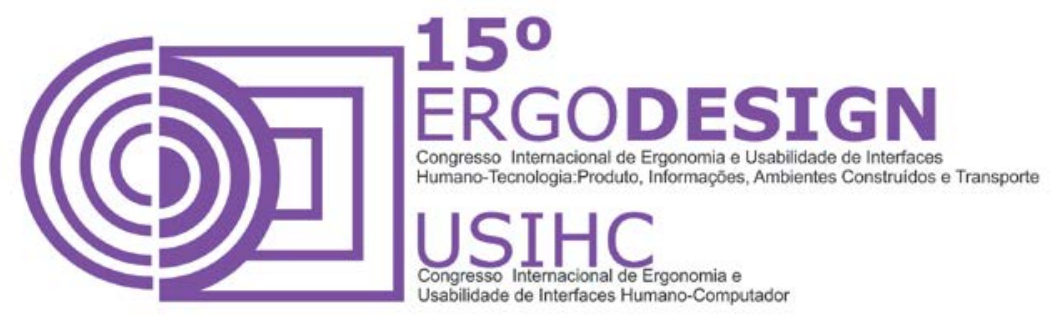

Brevemente dissertando sobre os termos legais, a constituição brasileira do ano de 1988 já prevê princípios sobre acessibilidade (BRASIL, 1988), e.g. com relação às normas arquitetônicas e urbanas, bem como ligados ao transporte coletivo. Porém, somente com o decreto número 5.296 (datado de 2 de dezembro de 2004), apareceram maiores providências sobre a promoção e o uso do desenho universal na legislação do Brasil (BRASIL, 2004). Apesar da existência deste decreto, não há uma regulamentação que direcione a produção de uma gama de produtos de forma geral ou setorizada dentro das diretrizes do desenho universal. Junto às normas técnicas brasileiras (NBR), as regulamentações com relação a realização de projetos inclusivos ficam restritas à acessibilidade de esfera arquitetônica, mobiliário urbano, transportes, auto-atendimento bancário e comunicação televisiva (CARLETTO; CAMBIAGHI, 2008).

Para lida (2005), a usabilidade significa facilidade e comodidade no uso dos produtos, tanto no ambiente doméstico como no profissional. lida, em concordância com Dul e Weerdmeester (2012) diz que produtos devem ser "amigáveis", fáceis de entender, fáceis de operar e pouco sensíveis a erros, assim como o sistema considera as características e necessidades do usuário, para que as operações sejam satisfatórias e eficientes. Por exemplo, quando sentamos em uma cadeira bem projetada, sentimos conforto e parece que somos bem recebidos. Em outros casos, há cadeiras que nos "agridem" e parece que querem nos expulsar, devido a uma relação "não-amigável" com o objeto.

Utilizar princípios de usabilidade que se encontram apenas em manuais e guias formulados em uma linguagem padrão pode não ser suficiente para alcançar a realidade desses trabalhadores, que estão imersos em uma variabilidade presente inclusive em sua cultura e aspectos cognitivos (ABRAHÃO, 2012).

\section{METODOLOGIA}

O método utilizado para a realização dessa pesquisa foi o estudo multicasos (YIN, 2005). Os estudos foram concentrados em lavouras de pequeno porte de cultivo de tomate das cidades de Itu e Presidente Prudente, ambas no estado de São Paulo, Brasil. Tais lavouras estão localizadas em pequenas propriedades agrícolas. Essa pesquisa teve caráter qualitativo, e foi composta por doze participantes, com idades de 18 a 54 anos, todos do sexo masculino. Foram utilizadas as técnicas de observações livres e entrevistas semiestruturadas nas abordagens realizadas junto aos trabalhadores, buscando captar os discursos e impressões desses profissionais acerca das práticas realizadas em suas atividades. A ênfase da presente análise situou-se sobre o uso dos equipamentos de proteção individual prescritos e/ou utilizados por esses trabalhadores na realização de sua atividade laboral. Na tabela 02 a seguir são expostas as etapas da presente pesquisa:

Tabela 02. Procedimentos metodológicos adotados pela presente pesquisa

\begin{tabular}{|l|l|}
\hline $\begin{array}{l}\text { 01. Revisão } \\
\text { bibliográfica }\end{array}$ & $\begin{array}{l}\text { Levantamento da fundamentação teórica sobre os temas de ergonomia, } \\
\text { normas sobre saúde e segurança no trabalho e desenho universal. }\end{array}$ \\
\hline 02. Coleta de & Realização de pesquisa in loco nas cidades de Itu e Presidente Prudente, \\
\hline
\end{tabular}




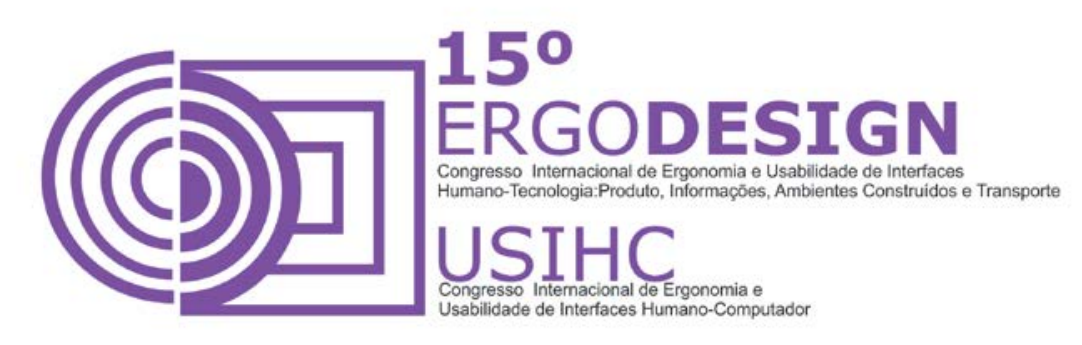

\begin{tabular}{|l|l|}
\hline dados & junto aos trabalhadores rurais. \\
\hline $\begin{array}{l}\text { 03. Análise dos } \\
\text { resultados e } \\
\text { construção de } \\
\text { hipóteses }\end{array}$ & Análise dos resultados obtidos e construção de hipóteses.explicativas \\
\hline $\begin{array}{l}\text { 04. Construção } \\
\text { das } \\
\text { considerações } \\
\text { finais }\end{array}$ & Elaboração da conclusão da pesquisa. \\
\hline
\end{tabular}

Fonte: Autores

\section{RESULTADOS E DISCUSSÃO}

Em ambas as propriedades analisadas, eram entregues por parte dos produtores os seguintes equipamentos de proteção individual: protetor respiratório descartável PFF1, luvas de látex e botas de Policloreto de Polivinila (PVC). Não eram fornecidos nenhum outro tipo de equipamento de proteção. Os EPIs eram armazenados de forma inadequada, próximos aos adubos e produtos químicos (agrotóxicos). Além disso, os respiradores, embora descartáveis, eram re-utilizados pelos trabalhadores. Não havia ficha de entrega de controle dos EPIs e os trabalhadores não eram instruídos em relação a sua utilização.

Os principais problemas encontrados foram: a falta de uso dos equipamentos de proteção individual associados a falta de treinamento, falta de higienização e guarda inadequada desses equipamentos.

Ao serem questionados sobre o porquê de não utilizarem os EPIs, os trabalhadores relatam que os mesmos são quentes e pesados, e acabam gerando desconforto durante os longos períodos de exposição ao sol adotando diferentes posturas, consumindo energia e aumentando a sensação térmica de calor.

Os trabalhadores afirmam que os EPIs não se adequam as suas atividades de trabalho. Acreditam que quem os desenvolve não tem contato direto com o tipo de trabalho que realizam nas propriedades familiares, que contam com pouco auxilio de tecnologias. Essa situação encontrada chama a atenção para uma maior necessidade de contato dos desenvolvedores desse tipo de produto com seus usuários finais, os quais soam estar situados em um patamar distante deste processo de desenvolvimento.

Entende-se que a própria natureza da tarefa traz desconfortos à saúde do trabalhador. O uso de equipamentos de proteção individual deveria aumentar sua segurança, conforto e serem adaptados às suas características psicofisiológicas (BRASIL, 1990).

As propostas do design universal podem se confrontar tanto com depoimentos e observações in loco como com as ponderações de Guérin et al. (2001), ao evocar propostas generalistas com relação aos indivíduos. Porém, autores atentam-se ao fato de que a universalidade literal do desenho de produtos tem caráter utópico (NEWELL; GREGOR, 2000; KEATES; CLARKSON, 2003), mas no entanto, essa abordagem tem a capacidade de 


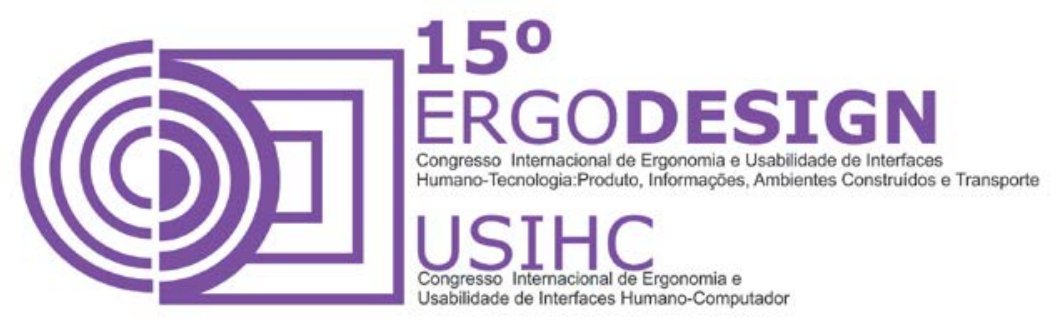

viabilizar produtos com uma maior sensibilidade a uma maior gama de diversidade de seus usuário, sendo assim interessante visualizar conceitos de DU no momento de desenvolvimento de produtos de proteção.

Os resultados deste trabalho apontam a importância dos EPIs incorporarem as reais necessidade das ações do sujeito na prática da sua atividade (relações de uso), na forma desse usuário poder agir naturalmente ou não com o auxílio do objeto concebido (FONTES, 2012).

\section{CONSIDERAÇÕES FINAIS}

O estudo da ergonomia em uma situação profissional está ligado ao desempenho que o indivíduo irá obter em seus processos. Umma melhor qualidade de vida do ser humano imerso nesse ambiente, logo, possui relação também com a interação existente entre o trabalhador e seus equipamentos de proteção individual nas diferentes ocupações laborais.

Na presente pesquisa, foi possível verificar que dentro do âmbito da agricultura de pequeno porte, focada na colheita de tomate, o uso desse tipo de equipamento ainda não é realizado com sucesso por inúmeros motivos, relacionados à falta de conforto, pouco entendimento sobre seu funcionamento e proteção oferecida ao trabalhador. A saída ligada a um desenvolvimento colaborativo e de ordem mais dinâmica entre os usuários finais e os desenvolvedores desses produtos é um apontamento a ser feito. Emerge a demanda por um detalhamento aprofundado por parte dos projetistas a respeito das reais condições de trabalho encaradas por estes trabalhadores.

O foco em diretrizes ligadas à usabilidade e em conceitos advindos do design, constituemse em um outro direcionamento para o qual este estudo busca chamar a atenção. Espera-se que desta forma que tal estudo colabore com as pesquisas na área, e chame a atenção para a necessidade de mais contribuições no campo de ergonomia e desenvolvimento de produtos relativos à proteção individual do trabalhador. Ressaltamos que é de extrema importância a compreensão da realidade do trabalho e a contribuição dos trabalhadores desde as etapas iniciais do projeto de criação ou adequação de equipamentos de proteção individual. Além disso, os testes realizados nesses equipamentos devem ser realizados in loco, para que o ambiente controlado laboratorial não mascare sua proteção frente a complexidade de elementos existentes na agricultura.

Enfatiza-se que o EPI deve ser entendido como interface entre o sujeito e o mundo, facilitando ou dificultando o desenvolvimento do trabalhador durante a realização de sua atividade. E que para atingir essa sinergia entre objeto facilitador entre sujeito e ação, projetistas e usuários precisam dialogar e construir coletivamente a solução, pautando-se em critérios: técnicos, no desenho universal (variabilidade dos indivíduos) e no trabalho real (usuários).

\section{REFERÊNCIAS BIBLIOGRÁFICAS}

ABERGO. Associação Brasileira de Ergonomia. O que é Ergonomia? Disponível em: http://www.abergo.org.br/internas.php?pg=0 que e ergonomia Acesso dia 6 de outubro de 2014.

ABRAHÃO, J. I. et al.. Ergonomia e Usabilidade em Ambiente Virtual de Aprendizagem. Ed. 


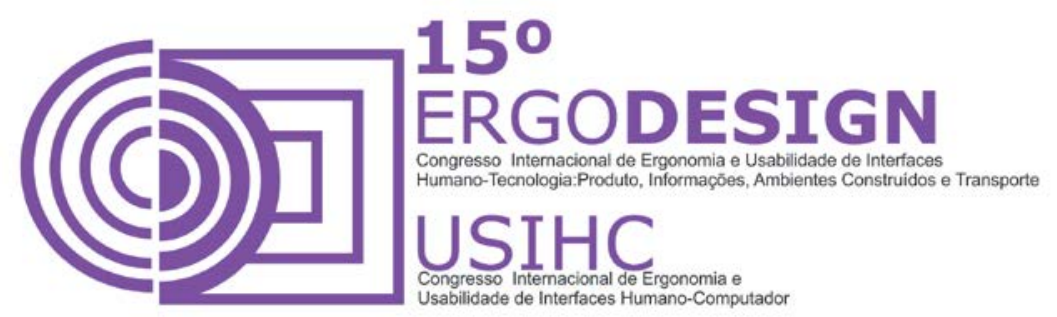

Blucher, 2012.

ALMEIDA, C. C.; PERLIN, H. S. S.; RUPPENTHAL, J. E. Uso do EPI e sua relação com as dermatoses ocupacionais na indústria da construção civil: um estado de caso. In: XXVIII COBENGE. Anais... 2000. Ouro Preto, 2000. 6 p.

BRASIL. Anuário Estatístico de Acidentes do Trabalho - AEAT. Ministério da Previdência Social. Ministério do Trabalho e Emprego. Disponível em: < http://www.mpas.gov.br/arquivos/office/1 130129-095049-870.pdf > Acesso dia 6 de outubro de 2014.

Constituição (1988). Constituição da República Federativa do Brasil. Disponível em: < http://www.planalto.gov.br/ccivil 03/constituicao/Constituicao.htm > Acesso dia 10 de julho de 2014.

Decreto $n^{\circ}$ 5.296, de 02 de dezembro de 2004. Regulamenta as Leis n.os 10.048, de 8 de novembro de 2000, que dá prioridade de atendimento às pessoas que especifica, e 10.098, de 19 de dezembro de 2000, que estabelece normas gerais e critérios básicos para a promoção da acessibilidade das pessoas portadoras de deficiência ou com mobilidade reduzida, e dá outras providências. Diário Oficial da União, Brasília, DF, 03 dez. 2004, Seção 1, n. 232, p. 5-10. Disponível em: < http://www.planalto.gov.br/ccivil 03/ Ato2004-2006/2004/Decreto/D5296.htm >. Acesso dia 29 de agosto de 2014.

Norma Regulamentadora $\mathrm{N}^{0}$ 6. NR 6. Equipamento de Proteção Individual - EPI. Ministério do Trabalho e Emprego. NR-6 - Equipamento de Proteção Individual. 2009. Disponível em: $<\quad$ http://portal.mte.gov.br/data/files/FF8080812DC56F8F012DCDAD35721F50/NR06\%20\%28atualizada\%29\%202010.pdf > Acesso dia 10 de outubro de 2014.

Norma Regulamentadora No 17. NR 17. Ergonomia. Ministério do Trabalho e Emprego.

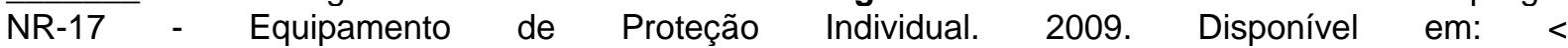
http://portal.mte.gov.br/data/files/FF8080812BE914E6012BEFBAD7064803/nr 17.pdf > Acesso dia 10 de outubro de 2014.

CARLETTO, A. C.; CAMBIAGHI, S. Desenho Universal: Um conceito para todos. São Paulo: Mara Gabrilli. 2008. 38 p.

COLEMAN, R. et al. From margins to mainstream. In: In: CLARKSON, P. J. et al.. (eds.) Inclusive Design: Design for the Whole Population. London: Springer-Verlag, pp. 250-269. 2003. p. 1-25.

FALZON, P. Ergonomia. São Paulo : Blucher, 2007.

FONTES, A. R. M. Ergonomia e design no projeto de espaços de trabalho: o balcão de atendimento dos Correios. $255 \mathrm{f}$. Tese (Doutorado em Engenharia de Produção). Departamento de Engenharia de Produção, Universidade Federal de São Carlos, São Carlos, 2012.

GROHMANN, M. Z. Segurança no trabalho através do uso de EPI's: estudo de caso realizdo na construção civil de Santa Maria. Segurança no Trabalho. Disponível em: < http://www.segurancaetrabalho.com.br/download/epis-construcao.pdf $>$ Acesso dia 08 de outubro de 2014.

GRUPO ERGO\&AÇÃO/DEP/UFSCAR. Fundamentos da Ergonomia. Caderno 1. Disponível em: < http://www.fat.uerj.br/intranet/disciplinas/Ergonomia/012004/Apostilas/Fundamentos\%20de\%20Ergonomia.pdf > Acesso dia 2 de outubro de 2014.

GUÉRIN, F. et al. Compreender o trabalho para transformá-lo: a prática da ergonomia. São Paulo: Edgard Blücher, 2001.

GUIMARÃES, E. A. de A. et al. Percepção de técnicos de enfermagem sobre o uso de equipamentos de proteção individual em um serviço de urgência. Cienc. enferm., Concepción, v. 17, n. 3, dez., 2011. 


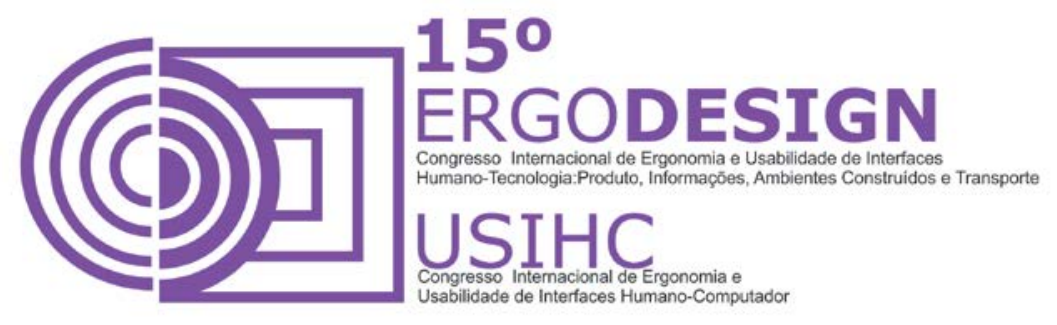

IIDA, I. Ergonomia Projeto e Produção. 2a edição revista e ampliada. Ed. Blucher, 2005.

KEATES, S.; CLARKSON, P. J. Countering design exclusion through inclusive design. In: CUU 2003 Conference on Universal Usability. Proceedings... 2003. New York: ACM Press, 2003. pp. 69-76.

LIMONGI-FRANÇA, A. C. Psicologia do Trabalho: psicossomática, valores e práticas organizacionais. São Paulo: Saraiva, 2008.

LOPES NETTO, A.; BARRETO, M. de L. C. A utilização do EPI neutraliza a insalubridade? Sociedade Brasileira de Engenharia de Segurança. Disponível em: < http://www.crori.org.br/biosseguranca/EPI\%20Neutraliza\%20a\%20Insalubridade.pdf $>$ Acesso dia 10 de outubro de 2014.

MONTEDO, U. B; SZNELWAR, L. I. Análise ergonômica do trabalho agrícola familiar na produção de leite. Prod. 2008, vol.18, n.1, pp. 142-154.

NEWELL, A. F.; GREGOR, P. User Sensitive Inclusive Design: in search of a new paradigm. In: CUU 2000 - Conference on Universal Usability. Proceedings... 2000. New York: ACM Press, 2000. pp. 3944.

NSCU. North Carolina State University The Center for Universal Design. Disponível em: < http://www.ncsu.edu/ncsu/design/cud/index.htm > Acesso dia 30 de agosto de 2014.

OLIVEIRA, H. C. de; SANTOS, J. S. P. dos; CRUZ, E. F. C. O Mundo do trabalho: concepções e historicidade. In: III Jornada Internacional de Políticas Públicas. Anais... 2007. São Luís, 2007. 9 p.

ORTOLAN, P. E.; FALCATO, M. G.; SOUZA, S. S. EPI - o que são? In: 5a Mostra Acadêmica UNIMEP. Anais... 2007. Piracicaba, 2007. 3 p.

PELLOSO, E. F.; ZANDONADI, F. B. Causas da Resistência ao Uso do Equipamento de Proteção Individual (EPI). Segurança no Trabalho. Disponível em: < http://www.segurancanotrabalho.eng.br/artigos/art epi cv.pdf > Acesso dia 08 de outubro de 2014.

SASSAKI, R. K. Inclusão: Construindo uma sociedade para todos (7a ed.). Rio de Janeiro: WVA, 2006.

SIMÕES, T. M. Medidas de proteções contra acidentes em altura na construção civil. 76 f. Monografia (Graduação em Engenharia Civil). Escola Politécnica, Universidade Federal do Rio de Janeiro, Rio de Janeiro, 2010.

TEIXEIRA, P. Equipamento de Proteção Individual - EPI. Fiocruz. Palestra. Disponível em: < http://www.cpqrr.fiocruz.br/posgraduacao/cienciasdasaude/apoio/Biosseguranca/65\%20\%20PedroEPI.pdf > Acesso dia 11 de outubro de 2014.

VANDERHEIDEN, G. C.; TOBIAS, J. Universal Design of Consumer Products: Current IndustryPractice and Perceptions. In: Human Factors and Ergonomics Society Annual Meeting, 2000. Proceedings... San Diego, California, 2000. pp. 19-22.

VEIGA, M. M. et al. A contaminação por agrotóxicos e os Equipamentos de Proteção Individual (EPIs). Rev. bras. saúde ocup. 2007, vol.32, n.116, pp. 57-68.

YIN, R. K. Estudo de caso: planejamento e métodos. 3a ed. Porto Alegre: Bookman, 2005. 